\section{The interaction of inflammatory cells in granuloma faciale}

\author{
Takeshi Nakahara, ${ }^{1}$ Yoichi Moroi, \\ Akari Tashiro,' Hiromaro Kiryu, \\ Masutaka Furue
}

'Department of Dermatology, Graduate

School of Medical Sciences, Kyushu

University, Fukuoka, Japan;

'Department of Dermatopathology, Kiryu

Clinic, Fukuoka, Japan

\begin{abstract}
Granuloma faciale (GF) is a rare chronic inflammatory skin disease characterized by single or multiple reddish-brown cutaneous plaques or nodules. Although this condition is benign, its clinical course is extremely chronic with poor response to therapy. The typical histopathological features of GF include vasculitis with mixed cellular infiltration; however, its etiopathogenesis remains unknown. Here, we describe the case of a 76-year-old man with GF resistant to topical steroids. Biopsy of the lesion revealed i) dense mixed inflammatory cellular infiltrates of lymphocytes, histiocytes, neutrophils, and eosinophils, ii) mild perivascular nuclear dust and swollen endothelium of blood vessels, and iii) a narrow Grenz zone beneath the epidermis. Immunohistochemical staining demonstrated mixed cellular infiltrates intermixed with $\mathrm{CD} \mathrm{a}^{+}$dendritic cells, CD68 ${ }^{+}$histiocytes, and $\mathrm{CD}^{+}$and $\mathrm{CD} 8{ }^{+} \mathrm{T}$ cells.
\end{abstract}

\section{Introduction}

Granuloma faciale (GF) is a chronic inflammatory skin disorder appearing as a solitary lesion or multiple reddish-brown infiltrating lesions on the face, usually on the cheeks, nose, and forehead. Although its etiopathogenesis remains unknown, vasculitis with mixed cell inflammation is considered to be the typical histological feature. ${ }^{1}$ Exposure to sunlight is regarded as a triggering factor; however, other causative factors such as infections, immunological disorders and associated malignancies might be responsible for its pathogenesis. ${ }^{2}$ Recently, the production of interleukin (IL)- 5 by the clonal T-cell population has been implicated in the attraction of eosinophils to the lesions. ${ }^{3}$ Here, we report a male patient who was clinically and histopathologically diagnosed with GF. Mixed cellular infiltrates intermixed with $\mathrm{CD}^{+} \mathrm{a}^{+}$dendritic cells (DCs), CD68 ${ }^{+}$histiocytes, and $\mathrm{CD}^{+}{ }^{+}$and $\mathrm{CD} 8{ }^{+} \mathrm{T}$ cells were detected immunohistochemically.

\section{Case Report}

The patient was a 76-year-old male who developed a reddish-brown cutaneous plaque with exaggerated follicular openings on the left cheek (Figure la and b). The lesion was slightly elevated and slowly progressive, and showed no response to topical steroids. No underlying associated disease was detected, and his routine laboratory examinations were all within the normal limits. Screening for antinuclear antibodies was negative. Clinically, GF, sarcoidosis, discoid lupus erythematosus, follicular mucinosis and pseudolymphoma were considered as differential diagnosis.

Punch biopsy from the lesion showed a dense dermal inflammatory and granulomatous infiltrate of mononuclear cells with numerous eosinophils and neutrophils. The features of mild leukocytoclastic vasculitis: perivascular neutrophilic infiltrate with debris and swollen endothelium of blood vessels were also evident. Stromal fibrosis was found around the granulomatous lesions. A narrow Grenz zone was also observed beneath the epidermis, and adnexal structure was intact (Figure $2 \mathrm{a}$ and $\mathrm{b}$ ). These histopathological findings were consistent with GF. Immunohistochemically, both CD8+ lymphocytes and $\mathrm{CD} 68^{+}$histiocytes were present mainly inside the granulomatous lesions (Figures $3 \mathrm{a}$ and b), whereas scattered $\mathrm{CD} 4^{+}$lymphocytes and $\mathrm{CD} \mathrm{a}^{+} \mathrm{DCs}$ surrounded the lesions, and to a lesser extent, occurred within the lesions (Figure $3 \mathrm{c}$ and $\mathrm{d}$ ). The cutaneous plaque lesion was treated with local injection of a corticosteroid. In a few months of treatment, infiltration was reduced but the reddish-brown cutaneous plaque lesion persisted.

\section{Discussion}

GF is a rare inflammatory skin disease with typical clinical and histopathological entity. A previous extensive review of $\mathrm{GF}$ comprising 66 patients revealed that more than $90 \%$ of the patients had only facial lesions and $62 \%$ of the patients of this series had a solitary lesion. GF has a tendency to appear in areas exposed to sunlight, such as the forehead, cheek, and nose. ${ }^{4}$ It is mostly asymptomatic but occasional burning or itching sensation is experienced. Dense granulomatous infiltration of lymphocytes, plasma cells, neutrophils, histiocytes and eosinophils is observed in the reticular dermis. Interestingly, a typical granulomatous lesion predominantly composed of histiocytes does not normally occur in GF, making GF one of the misnomers in dermatology. Fibrous tissue accompanying capillary proliferation can be observed in old lesions. One of the most important
Correspondence: Takeshi Nakahara, 3-1-1 Maidashi, Higashiku, Fukuoka 812-8582, Japan, E-mail: nakahara@dermatol.med.kyushu-u.ac.jp

Key words: granuloma faciale, dendritic cells, helper T cells, histiocytes

Received for publication: 2 August 2010.

Revision received: 25 October 20010.

Accepted for publication: 1 November 2010.

This work is licensed under a Creative Commons Attribution 3.0 License (by-nc 3.0).

() Copyright T. Nakahara et al., 2010

Licensee PAGEPress, Italy

Dermatology Reports 2010; 2:e17

doi:10.4081/dr.2010.e17
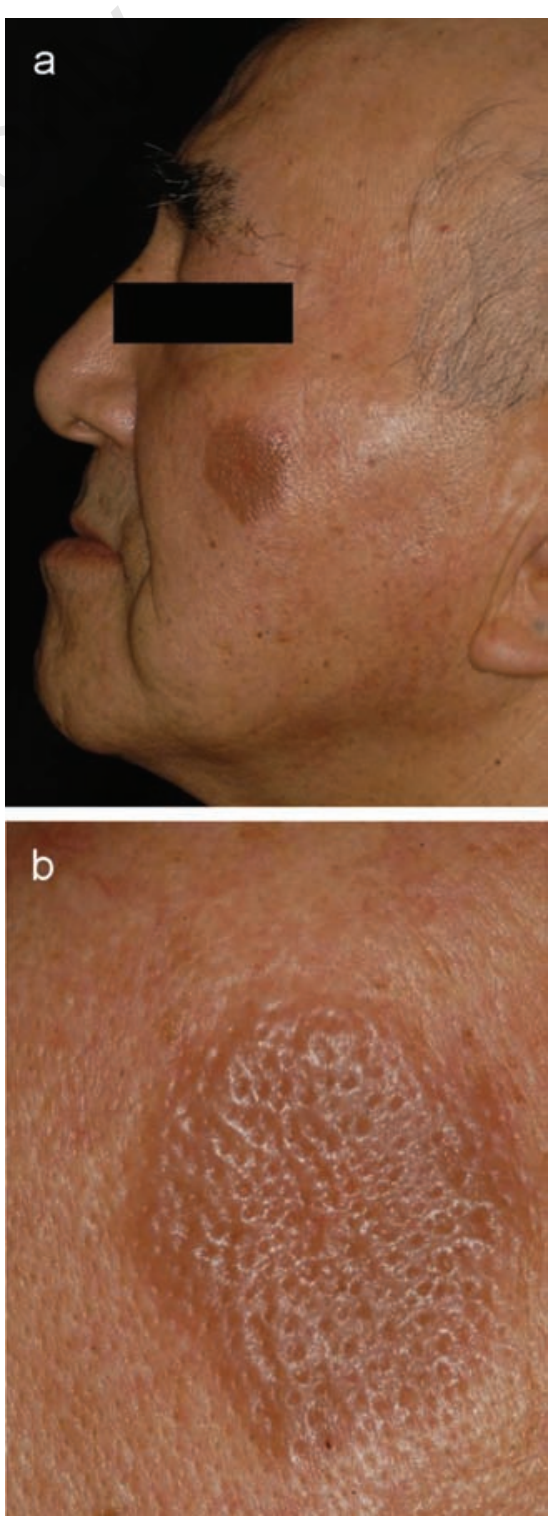

Figure 1. (a) Solitary, reddish-brown plaque on the left cheek. (b) Exaggerated follicular openings on the plaque. 

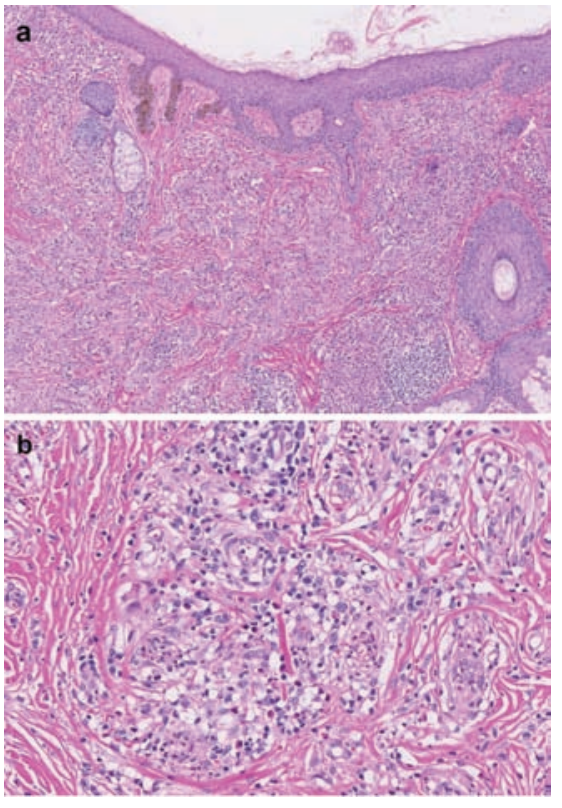

Figure 2. Histopathological characteristics of the plaque lesion. (a) A dense dermal inflammatory and granulomatous infiltrate of mononuclear cells with numerous eosinophils and neutrophils.(original magnification x40). (b) Mild leukocytoclastic vasculitis: perivascular neutrophilic infiltrate with debris and swollen endothelium of blood vessels are evident. Stromal fibrosis is observed around the granulomatous lesions. (original magnification $\times 400$ ).

histopathological findings in GF is the presence of the Grenz zone, which is an area between the epidermis and the upper dermis devoid of cells. ${ }^{1,4}$ Thus, the present case showed representative clinical and histopathological features of GF.

For the clinical differential diagnosis, sarcoidosis, lupus vulgaris, fungal infections, discoid lupus erythematosus, follicular mucinosis, and pseudolymphoma should be considered. ${ }^{1-4}$ Histopathological examination is useful in distinguishing GF from other diseases. Histopathological differential diagnosis of GF should be made with erythema elevatum diutinum (EED). Similar to GF, EED starts with the appearance of neutrophils and neutrophilic nuclear dust around small vessels containing fibrin in their wall. ${ }^{5}$ In most EED cases, the eruption is bilateral and symmetric. Histopa thologically, eosinophils are few or absent and neutrophils predominate with plasma cells only present episodically. The sites of EED predilection are different - the face is usually spared, and the skin on the dorsal aspects of joints is usually the target site.

Different etiologies regarding the pathogenesis of GF have been suggested, but most of them remain controversial. Because light-exposed areas are favored as exemplified in the majority of GF cases with facial involvement, actinic exposure has been suggested to play an important role. ${ }^{4}$ It is suggested that it may be a form of vasculitis mediated by localized Arthus-like
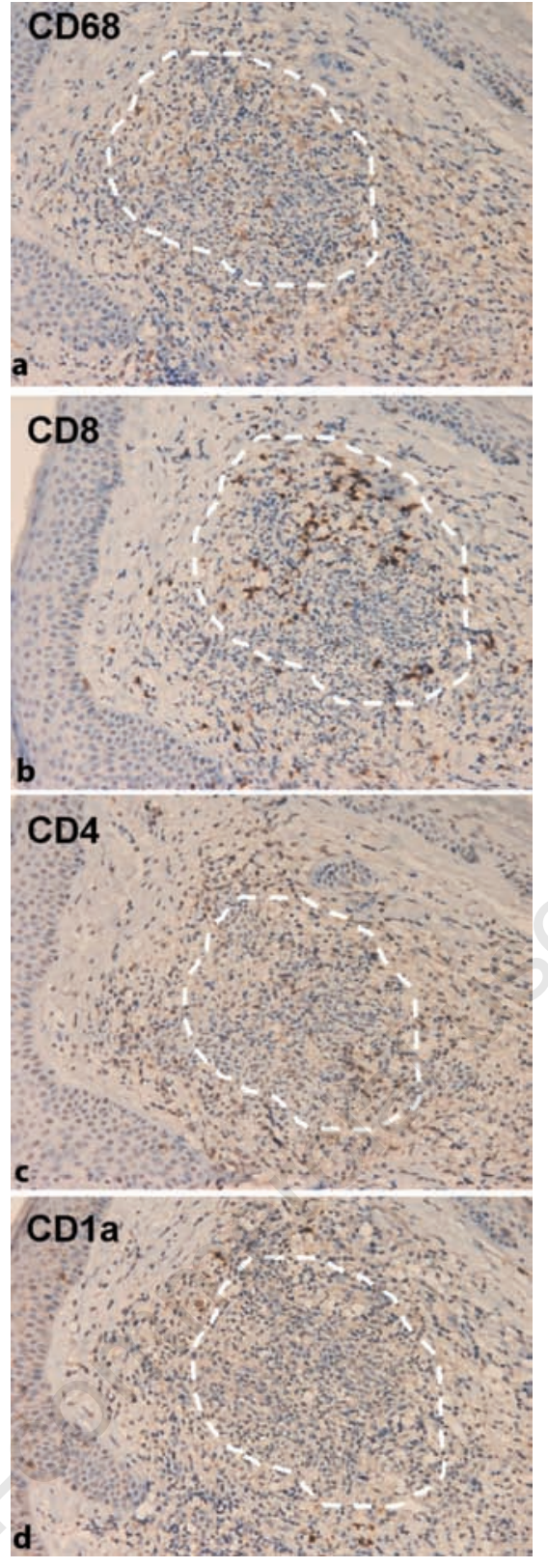

Figure 3. Predominant infiltration of $\mathrm{CD}^{+} 8^{+}$histiocytes (a) and CD8+ lymphocytes (b) into the granulomatous lesions, and $\mathrm{CD}^{+}$lymphocytes (c) and $\mathrm{CDIa}^{+}$ dendritic cells (d) around the lesions.

response. ${ }^{6}$ It might also be due to a localized persistent immune complex disease or persistent allergic hypersensitivity reaction to a retained antigen or both. ${ }^{6}$ Selvaag and Roald showed in their immunohistochemical study of $\mathrm{GF}$ that eosinophils have a strong reaction to eosinophil cationic protein antibodies, and are activated; thus, they claimed that eosinophils play an important etiologic role. ${ }^{7}$ Immunohistochemically, $\mathrm{CD} 4^{+}$lymphocytes and a high lesional production of IL-5, a cytokine important for eosinophil recruitment ${ }^{3}$ were observed. In line with previous reports, our results suggest that the interaction between DCs and helper T cells might be one of the important factors for the for- mation of lesions because DCs can modulate helper T cell functions such as cytokine production. Although multiple treatments of GF have been attempted, beneficial therapeutic effects have not yet been observed. Local therapies have also been used, including surgical excision, cryotherapy, and laser therapy; ${ }^{8}$ however, most of these may result in pigmentation changes or scarring. Recently, a number of reports on the successful use of tacrolimus in GF have been published. ${ }^{9,10}$ Tacrolimus decreases the number of Langerhans cells and antigen-presenting cells in the skin and inhibits the propagation of the inflammatory cascade. Because an immunopathological etiology is suspected in our study and previous reports, it was assumed that local control of the interaction of DCs and helper T cells by topical immunosuppressants may show a positive therapeutic effect.

\section{References}

1. LeBoit PE. Granuloma faciale: a diagnosis deserving of dignity. Am J Dermatopathol 2002;24:440-3.

2. De D, Kanwar AJ, Radotra BD, Gupta S. Extrafacial granuloma faciale: report of a case. J Eur Acad Dermatol Venereol 2007;21: 1284-6.

3. Gauger A, Ronet C, Schnopp C, et al. M. High local interleukin 5 production in granuloma faciale (eosinophilicum): role of clonally expanded skin-specific CD4+ cells. Br J Dermatol 2005;153:454-7.

4. Ortonne N, Wechsler J, Bagot M, et al. Granuloma faciale: a clinicopathologic study of 66 patients. J Am Acad Dermatol 2005;53: 1002-9.

5. Konohana A. Extrafacial granuloma faciale. J Dermatol 1994;21:680-2.

6. Marcoval J, Moreno A, Peyr J. Granuloma faciale: a clinicopathologic study of 11 patients. J Am Acad Dermatol 2004;51:26973.

7. Selvaag E, Roald B. Immunohistochemical findings in granuloma faciale. The role of eosinophilic granulocytes. J Eur Acad Dermatol Venereol 2000;14:517-8.

8. Ludwig E, Allam JP, Bieber T, Novak N. New treatment modalities for granuloma faciale. Br J Dermatol 2003;149:634-7.

9. Marcoval J, Moreno A, Bordas X, Peyrí J. Granuloma faciale: treatment with topical tacrolimus. J Am Acad Dermatol 2006;55: S110-1.

10. Tomson N, Sterling JC, Salvary I. Granuloma faciale treated successfully with topical tacrolimus. Clin Exp Dermatol 2009;34:424-5. 